\title{
Странищы истории
}

\section{РОССИЙСКОЕ ГОСУДАРСТВО И ДИПЛОМАТИЧЕСКОЕ ПРАВО. ИСТОРИЯ И СОВРЕМЕННОСТЬ}

\author{
A.Ю. С е м в я н о в a $^{*}$
}

В настоящее время основным международно-правовым источником дипломатического права является Венская конвенция о дипломатических сношениях 1961r. Формирование статей Венской конвенции 1961г. имело под собой глубокие исторические корни. Большинство статей, принципов конвенции возникло в результатс исторически сложившейся дипломатической практики, правил ведения межгосударственных сношений, начавших свое развитие в виде обычаев в глубине веков. Представляется возможным проследить это на примере развития дипломатического права Российского государства.

Первоначально все международные отношения России велись самими князьями. В тех случаях, когда князья не принимали личного участия в ходе переговоров, дипломатические отношения осушествлялись посредством послов. Находясь в иностранном государстве, они заменяли своего князя, действуя от его имени, и тем самым представляя его. С образованием в конце XV века централизованного государства, послы становятся государственными лицами. Не случайно право представлять собой особу государя выделялось и являлось одновременно обязанностью послов. Послы являлись как бы лицом своего государства. Венская конвенция в п.а) п.1 ст.3 первой функцией дипломатического представительства отмечает: представительство аккредитующего государства в государстве пребывания.

Древние дипломатические памятники отражают, в частности, такой документ, удостоверяющий полномочия послов, имеющий представительный характер, как “верюшая грамота".

Венская конвенция, используя понятие "верительная грамота" в п.1 ст.13 закрепляет, что "глава представительства считается приступившим к выполнению своих функций в государстве пребывания, в зависимости от практики, существующей в этом государстве, которая

* Аспирантка кафедры государственного и международного права Казанского государственного университета. 
должна применяться единообразно, либо с момента вручения верительных грамот, либо с момента сообщения о своем прибытии и представлении заверенных копий верительных грамот министерству иностранных дел государства пребывания или другому министерству, в отношении которого имеется договоренность".

"Верющую грамоту" послы вручали на первой торжественной аудиенции у главы иностранного государства. Ф.Сергеев дает следующее определение "верющей грамоты" - документ, удостоверяющий назначение указанных в нем лиц и свидетельствующий о том, что поручения, передаваемые дипломатическими агентами, адресуются от имени государя, их направившего. " “Верительные грамоты" обычно выдаются главам дипломатических представительств первых двух классов. В науке международного права "верительные грамоты" определяются как документ, удостоверяющий представительский характер дипломатического представителя и аккредитующий его в иностранном государстве. Как видно, определения очень схожи.

Современный дипломатический протокол сохранил также требования к обязательным составным элементам "верительных грамот", таким, как: титулование главы государства; фраза, мотивирующая назначение дипломатического представителя; просьба верить всему тому, что будет излагать дипломатический представитель от имени главы своего государства; состояние дипломатических отношений между странами и т.д." "Верющие грамоты" имели следуюшую форму: начинались они титулом царя, потом, в случае ранее имевшего место со стороны иностранной державы посольства в Россию говорилось о том, что приезжал в Россию ее посол, что “верющий лист” его был принят, а речи его были выслушаны, потом объявлялось желание быть в дружественных отношениях, затем рекомендовали "посла верного нашего с нашими речьми и что будет такое от нас говорити, и твоя бы светлость прав уверия, т.е. наши речи". 3 После учреждения Посольского приказа (1549г.) формуляр верюшей грамоты был строго установлен и не менялся. ${ }^{4}$

Таким образом, "верительные (верющие) грамоты" изначально удостоверяли представительный характер деятельности дипломатического представителя. Сохранились и обязательные составные элементы структуры документа. Авторы “Курса международного права" не случайно подчеркивают, что функция представительства по Венской конвенции 1961г. является основной. Вся деятельность посольства - это представительство...5 Положение о Посольстве Российской Федерации, утвержденное Указом Президента Российской Федерации от 28.10.96г. №1497 закрепляет, что основными задачами и функциями Посольства Российской Федерации являются представительство Российской Федерации в государстве пребывания.

Русская дипломатика (как наука о документах) относит “верительные (верюшие) грамоты" в разряд публично-правовых актов светских властей, имеющих удостоверительный и договорно-удостоверительный Вид. 6

Пункт 1 ст.13 Венской конвенции 1961г. не случайно подчеркивает наличие особенностей дипломатической практики в государствах. Так, например, отдельные нормы дипломатического протокола, 
называемые церемониалом имели место уже на раннем этапе развития, в частности, российской дипломатии. В Древней Руси отмечался так называемый дипломатический обряд, внешние приемы дипломатических сношений, дипломатический этикет. Окончательное формирование дипломатического церемониала в литературе приходится на XVI-XVII в.в. ${ }^{7}$ Существовал и свой церемониал вручения "верюших грамот". Современный протокол вручения верительных грамот описывается И.П.Блищенко. ${ }^{8}$

Международному праву известны “сложившиеся издавна обычные нормы, предусматривавшие такие обшепризнанные функции дипломатических представительств, как переговоры, информационная деятельность". Сбор информации издавна входил в обязанности посла. K примеру, иностранные послы в Москве конца XV - начала XVII в.в получали разрешение передать определенное известие своему правительству только в том случае, если с ним предварительно ознакомится сам царь. Это и ряд других ограничений было связано с опасениями дипломатического шпионажа. Так, предоставление свободы послам после первой аудиенции у царя стало нормой лишь в XVII веке.$^{10} \mathrm{Ha}$ посольских встречах обсуждались принципиальные проблемы будушего договора, его конкретные статьи. Прежде чем переходить к непосредственным переговорам послы разменивались "верющими грамотами", и только потом приступали к переговорам. Все переговоры велись через бояр и других лиц, т.е. московские цари этим не занимались, в отличие от более раннего периода, включая XI век, когда сами князья принимали личное участие в переговорах.

Таким образом, перечисленные функции дипломатических представительств, определяемых Венской конвенцией 1961г. имеют безусловно историческую основу.

Наличие посольской иерархии уже, как отмечается исторической наукой, можно предположить из договора Руси с Византией 907r. Места имени представителей при перечислении состава посольства выбирались (указывались) не случайно. Сушествовало понятие “обычного”, “рядового” посла.

K началу XVI века в России были сформированы три основных разряда дипломатических представителей:

1) послы - "великие послы";

2) посланники - “легкие послы";

3) гонцы.

Ключевое различие между разрядами состояло в объеме полномочий, сословной принадлежности. Социальный статус и ранг дипломата должны были быть подтверждены определенным количеством свиты. ${ }^{11}$

За период с 1645-1676гг. было принято особенное распределение дипломатических агентов и по государствам, и по званию посылаемых лиц. Чиновники разделялись на 13 степеней. Каждый род занимал определенную степень. На этом было основано назначение различного ранга послов К иностранным государям. В отношении порядка вручения "верительных грамот" в России при Елизавете Петровне устанавливается обычай допускать $\mathrm{K}$ аудиенции только 
дипломатических представителей высшего ранга. Остальные дипломатическиепредставители могли вручать свои грамоты только в ведомстве иностранных дел. Такое общепризнанное правило как приоритет дипломатических представителей высшего ранга было закреплено Венским (1815г) и Аахенским (1818г) актами. В них говорится о том, что послы, посланники и министры-резиденты аккредитуются при главах государств, а поверенные в делах - при министрах иностранных дел. ${ }^{12}$

Первая международная классификация, установленная постановлениями Венского и Аахенского конгрессов, просуществовала до Венской конвенции 1961 г. из которой исчез только класс министров-резидентов между классом посланников и классом поверенных в делах. Статья 14 Венской конвенции 1961г. дает следуюшую классификацию глав представительств:

- класс послов и нунциев, аккредитуемых при главах государств и других глав представительств эквивалентного ранга;

- класс посланников и интернунциев, аккредитуемых при главах государств;

- поверенных в делах, аккредитуемых при министрах иностранных дел.

Класс, к которому должны принадлежать главы дипломатических представительств, определяется соглашением между государствами (ст.15 Венской конвенции от 1961г).

Различие в отношении старшинства и этикета дипломатических представителей (по п.2 ст.14 Венской конвенции 1961г.) также имеет историческую основу. Скажу, к примеру, что "корм" иностранным дипломатам в истории Российского государства выдавался также в зависимости от их ранга. Л. Юзефович отмечает, что уже при Федоре Ивановиче приглашения к царскому столу становятся все более редкими. Дипломатам низшего ранга посылались на подворье блюда с дворцовой кухни. Длина стрелецкого строя на пути следования послов также была различной для послов, посланников и гонцов. ${ }^{13}$

Кроме того, дипломатические курьеры (см: ст.27 Венской конвенции 1961г.) очень схожи по функциональным признакам с низшим классом гонцов дипломатических представителей Российского государства.

При анализе ст.15 Венской конвенции 1961г. действительно можно привести исторические примеры договорного определения класса, к которому должен принадлежать дипломатический представитель. Например, “... Российский Императорский Двор будет всегда при Блистательной Порте иметь второго ранга министра, т.е. посланника, или полномочного министра...". 14

Исторически сложилось так, что дипломатический иммунитет в целом всегда рассматривался как правовое установление, закрепленное сначала в обычных, а затем и в договорных нормах международного права. 15 При анализе ст.2 "А оже убьют новгородца посла за морем или немецкым посол Новгороде, то за ту голову 20 гривн серебра", и ст.15, что вводит двойной штраф за убийство заложника и священника (обычного члена посольства), договора Новгорода с Готским берегом 1189-1199гг., авторы "Памятников русского права" 
пришли к выводу, что “в феодальном праве неприкосновенность посла, какправило, сочеталасьснеприкосновенностьюсвященникаивсехлиц, находившихся под патронатом церкви. А ст.15 и ст. 2 фактически являются зародышами постановлений о дипломатическом иммунитете". ${ }^{16}$ Кроме того, договоры 911 г. и 914 г. с Византией говорят о возможности кровной мести в случае убийства посла как с византийской стороны, так и с русской. За удары мечом, копьем или каким-либо другим оружием платили определенным количеством серебра, а при случае того, что преступнику нечем было платить, требовали от него клятвы в соответствие с обычаями своей веры, что у него действительно ничего нет.

Л.А. Юзефович отмечает, что "право посольской неприкосновенности в средние века было законом, причем тем более незыблемым, что покоился он не на букве, а на обычае... Тем не менее русский (и не только русский) посольский обычай знал и письменные гарантии неприкосновенности прибывших в страну иностранных дипломатов...". ${ }^{17}$ Речь идет о так называемых “опасных грамотах". Этим письменным актом утверждались письменные гарантии неприкосновенности иностранных дипломатов. "Опасные грамоты" заранее доставлялись монарху, намеренному отправить посольство. Также русские послы могли выдавать иностранным послам "опасные грамоты" на проезд их в Россию и обратно, со своей подписью и печатью, посланникам такие грамоты давались из Посольского приказа.

Данная грамота имела обычно свой стереотип: “.....Кого к нам пошлешь своих послов и тем твоим послом к нам приехати и от нас отъехати со всеми их людьми безо всякие зацепки, на обе стороны путь чист”. Однако здесь не учитывается явная связь с такой разновидностью грамот как "проезжая грамота". Ей как раз дается определение как письменного свидетельства, выдававшегося отдельным лицам, дипломатическим агентам, купцам для беспрепятственного ("без зацепок") проезда по территории иностранного государства. Выдавались такие документы обычно от имени государства, по территории которого следовали иностранные дипломатические лица.

“Проезжие грамоты" обеспечивали свободный, беспрепятственный проезд по территории своего государства, и выдавались не только государем страны, куда направлялись чужеземные послы, но и государем страны, которую представляют эти "путешественники". ${ }^{18}$ Государь страны, куда были посланы иноземные дипломатические агенты мог адресовать данную им “проезжую грамоту" правителю третьего государства с просьбой о пропуске таких уполномоченных через его владения. Эти грамоты посылались с особыми чиновниками, или гонцами, прежде послов, чтобы им “очистить дорогу".

Дипломатика однако не дает классификацию "проезжим грамотам", a "опасные грамоты" относит к тому же виду, что и "верительные (верюшие) грамоты". Соборное Уложение 1649г. имеет отдельную главу 6 "О проезжих грамотах в иныя государства". В ней 6 статей. Венская конвенция 1961г. в ст.25 в общей форме указывает об обязанности принимающего государства предоставлять дипломатическому представи-тельству все возможности для выполнения функций представи- 
тельства, а в ст. 26 прямо говорит об обеспечении всем сотрудникам представительства свободу передвижения по территории государства пребывания иностранного дипломатического представительства. Такова история права дипломатов на свободное передвижение.

Право на неприкосновенность выделяется отдельно из тех прав, которыми обладали послы, не зависимо от их ранга. Россия признавала неприкосновенность иностранных послов, за исключением случаев когда: они проезжали по территории России без разрешения, путем обмана, тайно: они были шпионами; либо были должниками кому-нибудь из русских. ${ }^{19}$

Пример известного инцидента с русским послом А.А. Матвеевым, подвергшимся в Лондоне 21 июля 1708г. нападению и аресту, показывает настойчивость российского государства, требующего уважения, неприкосновенности русских послов. Данный инцидент послужил причиной для принятия английским парламентом специального акта, осуждающего действия против А. Матвеева и поводом для законодательного оформления права посла на неприкосновенность. Парламентский акт был принят 21.04.1709г. (“О сохранении привилегий послов и публичных министров от иностранных государей и чинов”). Речь шла о грубейшем обесчестии чрезвычайного посла "онаго заарестовали, силой на большой улице из кареты вывели и несколько часов держали под арестом". Подчеркивалось, что послы и иные дипломатические агенты обладают правами и привилегиями и "свято, ненарушимо подобают быть соблюдаемы". Соответственно в отношении упомянутого посла все начатые процессуальные действия, иски признаются недействительными и "будут считаться таковыми, с какими бы намерениями, видами и целями они не были возбуждены". 20

В выработке текста данного документа приняли участие и иностранные дипломаты. В Петербурге британский представитель Витворт вручил Петру Первому личное послание королевы с извинениями за происшедший инцидент. В нем сообщалось также о наказании виновных лиц и издании акта, исключающего подобное в будущем. ${ }^{21}$

Как правило, членов посольской свиты, совершивших преступления в России, русские власти не наказывали сами, а требовали их наказания от правительства той страны, откуда они прибыли. Данная обычная норма подчеркивает не столько подчинение русской дипломатической практики теории экстерриториальности, присутствуюшей в международном праве, сколько подтверждает исторический характер п.1 ст.31 Венской конвенции 1961г., в соответствии с которой от уголовной юрисдикции государства пребывания дипломатический агент полностью освобождается.

Однако, существовало ранее и правило взаимности или реторсии, когда на оскорбление русских послов за границей, русское правительство отплачивало тем же иностранным послам, прибывшим в Россию, либо прерывало дипломатические отношения с такой державой. В противном случае, когда со стороны иностранных держав не было никаких притязаний в отношении русских послов, людям, оскорбив- 
шим иностранного посла или его свиту на территории Российского государства ждалотяжелое наказание.

Высшие лица подвергались царской опале, и сверх того "выдавались головою" оскорбленному, а низшие наказывались “батогами”. Несмотря на прочно устоявшуюся практику права посольской неприкосновенности, нарушение его в истории имело место. Сюда относятся и реторсии, о которых указывалось выше, а также вымогательство, избиения, грабежи.

Освобождение дипломатического агента от обязательства дачи показаний в качестве свидетеля, как отмечается авторами "Курса международного права" (п.2 ст.31 Венской конвенции 1961г.) также является давним международно-правовым обычаем. Пример неприкосновенности архивов и документов в любое время и независимо от их местонахождения (ст.24 Венской конвенции 196Іг.) в русской дипломатической практике можно привести следующий: когда с 1623 г. было принято правило: "Если посол, посланник или гонец окончит дни в царстве одного из трактуюших государей,... то он должен приказать сохранить все имущество его, бумаги и прочие вещи и доставить при случае в отечество. Равным образом должно было поступать и в случае кораблекрушения". ${ }^{22}$ Речь идет о трансформации обычной нормы международного права, когда неприкосновенность резиденции дипломатического агента распространяется на все предметы, имущество дипломата ( на которое исключается применение принудительных мер исполнения судебных решений).

Таким образом, большинством фундаментальных норм и принципов современного дипломатического права, закрепленных в Венской конвенции 1961г. были подтверждены ряд обычных норм (обычаи, обыкновения, писаные и неписаные правила) берущих свое начало глубоко в истории. А история Российского государства в этом не исключение и является богатой почвой для рассмотрения эволюции норм международного права.

${ }^{1}$ См. Сергеев $Ф$. Формирование русского дипломатического языка. - Львов.: - Издательство при Львовском университете, 1978. - С. 165.

${ }^{2}$ См. Молочков $\Phi$. Дипломатический протокол и дипломатическая практика.

- М.: Международные отношения, 1977. - С. 58 - 59.

${ }^{3}$ Сахаров A. Дипломатические обычаи древней России. - Отрывки из журнала Русская история, кн.9 - отд. 1, кн.11 - отд.1 - кн.12 - отд.1, Ч.3 - С. 20.

${ }^{4}$ Рогожин Н., Чистякова Е. Посольский приказ // Вопросы истории. - 1988. №7. - C. 119.

${ }^{5}$ Курс международного права. в 6-ти томах - М.: Наука, 1990. - Т.4. - С. 113.

${ }^{6}$ С. Каштанов С. Русская дипломатика. - М.: Высшая школа, 1988. - С. 151.

${ }^{7} \mathrm{CM}$. История дипломатии. - М.: Гос.изд-во политической литературы, 1950. - T.1. - C. 235.

${ }^{8}$ См. Блищенко И. Дипломатическое право. - М.: Высшая школа, 1990. C.55.

${ }^{9}$ Курс международного права. в 6-ти томах - М.: Наука, 1990. - Т.4 - С. 113. 
${ }^{10}$ См. Юзефович Л. Как в посольских обычаях ведется... - М.: Международные отношения, 1988. - С. 77, 80.

1 См. Юзефович $Л$. Русский дипломатический обычай // Международная жизнь. - 1988. - №8; Белокуров С. О посольском приказе. - М.: Изд-во ИМО, 1962.

${ }^{12}$ См. Кожевников $Ф$. Русское государство и международное право. (До ХХ века). - М.: Юрид. изд. тип. им. Е.Соколовой, 1947. - С. 200; История дипломатии. - М.: Гос. Изд-во полит.лит-ры, 1950. - Т.1. - С. $261-269$.

${ }^{13}$ См. Юзефович $Л$. Как в посольских обычаях ведется... - М.: Международные отношения, 1988. - С. 131, 90.

14 Трактат, заключенный между Россией и Турцией при Кучук-Кайнарджи от 10.07.1774r. Арт.5; Договор России с Кореей от 25.07.1884r. // Собрание важнейших трактатов и конвенций, заключенных Россией с иностранными державами (1774 - 1906rг.). - Варшава.:, 1906. 119.

15 Курс международного права. в 6-ти томах - М.: Наука, 1990. - T.4. - С.

16 Памятники русского права. вып.2. - М.: Госюриздат, 1953. - С. 124.

17 Юзефович Л. Как в посольских обычаях ведется... - М.: Международные отношения, 1988. - С. 41 .

$18 \mathrm{CM}$. Сергеев $\Phi$. Формирование русского дипломатического языка. Львов.: Изд-во при Львовском ун-те, 1978. - С. 179. 16.

${ }^{19}$ См. Сахаров А. Дипломатические обычаи древней России, Ч.3. - С.13-

20 Цит. по: Александренко В. Русские дипломатические агенты в Лондоне в XVIII веке. - Варшава.: 1897. - T.2. - С. 16 - 18.

21 См. Пескова Г. А.А. Матвеев 1666-1728 гr. // Вестник МИД СССР. 15.05.1990. - № $9 / 67 .-$ С. 71 .

22 Сахаров A. Дипломатические обычаи древней России, Ч.3. - С. 15 - 16.

г. Казань

Статья поступила в редакцию в июне 1999 г. 